\title{
Impact of Total Quality Management Practice on Small and Medium Scale Enterprises in Nigeria. (A Case Study of Small Business Owners in Lagos).
}

\author{
Samuel Olumuyiwa Olusanya ${ }^{1,}$ Eunice Abimbola Adegbola ${ }^{2}$ \\ Lecturer National Open University of Nigeria, School of Art and Social Sciences, Economics Unit ${ }^{1}$ \\ Lecturer National Open University of Nigeria, School of Management Sciences, Marketing Unit ${ }^{2}$
}

\begin{abstract}
The paper takes a look at the impact of total Quality Management Practice on Small and Medium Scale Enterprises in Lagos State: a case study of Small business owners in Lagos. However, the paper makes use of primary data of questionnaire analysis and the objectives of the paper is to examine the impact of total quality management practices on Small and Medium Enterprises in Nigeria and to identify the challenges encountered by the SME in adopting successful quality management programmes within their organization. Moreover, two hypotheses were tested using the spearman's rank correlation coefficient and the result revealed that total quality management practices have a significant effect on Small and Medium Enterprises in Nigeria and challenges encountered by the SME has lead to successful total quality management programmes within their organizations. The paper concludes that Quality management is focused not only on product/service quality, but also the means to achieve it Quality management, therefore uses quality assurance and control of processes as well as products to achieve more consistent quality. Finally, the paper then recommends that Good quality management programmes should be in place in the organization to enable all the staffs to learn and undergo the process of quality management in their organization.
\end{abstract}

Keyword: Quality Management Practice, Small and Medium Scale Enterprises, Small Business Owner, Spearman's rank correlation coefficient, Product/service quality, Quality Assurance, Management programme.

\section{Introduction}

In today's world, organizations are facing the growing challenges from global competition and more sophisticated customers in terms of what they want and their changing needs. The ever-increasing global competitive nature of the business environment has forced corporations to develop strategies to become low cost producers and to differentiate their goods and services from their competition. Through customer-focused quality programmes, quality lowers the cost and will become a powerful product differentiation to customers. (Ajayi, 2013).

In order to be successful, firms must view quality as an essential part of their strategic process. Quality is a term that carries important meaning to both producer and customer. In the global market place today, many organizations realized that its survival in the business world depend highly on producing high quality product and services. Indeed, a lot of organizations have emphasized that quality should have to be put in place, integrated within the management system, especially in terms of bringing the end products or services to the customers, especially with the intense competition arriving from the rivals. (Oluseye, 2014).

Accordingly, quality management $(\mathrm{QM})$ has become increasingly prevalent as one of the management strategies in ensuring customer satisfaction and loyalty, improving products and service quality and reinforcing continuous improvement. This paper is tailored along this line, and seeks to evaluate the level of awareness of quality management practices of small and medium scale enterprises (SMEs) in Nigeria. Small and medium size enterprises (SMEs) are the life blood of modern economies. SMEs play a unique role in countries industrial development in terms of employment creation, income generation and ensuring equitable distribution of limited resources. Unfortunately, while an overwhelming percentage of Nigeria businesses are SMEs, the performance of the SME sector has remained dismal towards the drive for economic development and this has in turn contributed to low performance of larger businesses as well (Onugu, 2005).

In Nigeria, the SME sector's contribution has fallen short of its potential due largely to lack of effective quality management and coordinated effort to support SME's operations. Most Nigerian SMEs struggle to operate, manage and improve their businesses efficiently in order to consistently deliver quality products and services on time (Osuagwu, 2008). Among the numerous challenges to increase performance and growth of most of these companies include quality management practices. That they should remain competitive and 
produce high quality outputs is of importance not only at the macro level but also to larger organisations; because SMEs are often suppliers of goods and services to larger organizations and lack of product quality would adversely affect the competitive ability of the larger organizations.

Previous work on the subject of Quality Management and some other contribution on related subjects have indicated that there exist considerable potential benefits in implementing QM. It seems however that the awareness of the concept and its principles is still very low in developing countries, most especially in small and medium scale enterprises (SMEs), and therefore, not much has been done to actualise the benefits. According to Goh and Ridgeway (1994), SMEs have been slow to adopt quality management techniques in comparison with large organisations in less developing countries.

However, whatever the size of the enterprise, quality plays a very important role in its success. Although there is much evidence in the literature of research being carried out in established economies, it is evident that there is a limited amount of research being undertaken concerning Quality management (QM) in developing countries. Gosen et al. (2005) stated that: "A number of gaps are identified in the literature on quality management in developing countries along with significant challenges including differing Perceptions of quality".

Therefore, the objectives of the study is to examine the impact of total quality management practices on Small and Medium Enterprises in Nigeria and to identify the challenges encountered by the SME in adopting successful quality management programmes within their organisations.

\subsection{Literature Review}

\section{Literature Review And Theoretical Framwework}

A review of literature was conducted to gain an understanding of the nature of the problem regarding the quality management practices in SMEs in Nigeria and internationally. There is considerable literature covering quality management in SMEs in developing countries which aided in providing a general understanding of what challenges SMEs face in their operations. However, little or no research has been conducted with regards to the quality management practices and issues of SMEs in Nigeria. Therefore, extensive searching was conducted to discover sources that would be of benefit to the researcher. The literature reviewed does, however, provide good insight into the general condition of quality and quality practices in Nigeria.

\subsection{Definition Of SMES}

Small to Medium Size Enterprises (SME's), in the European Commission (2005) User Guide entitled the New SME Definition, is quoted as saying "(SME's) are the engine of the European economy" and are further cited as 'the largest group of businesses in Europe (USHER, 2004). Current statistics do vary, but a general view is that more than $90 \%$ of companies fall into the 'SME' category, with nearly $60 \%$ being small businesses having less than 10 employees (Micro). According to the European Commission (2005) in the enlarged European Union some 23 million SME's provide around 75 million jobs and represent $99 \%$ of all enterprises. More country specific, in the UK at present there are over 3.7 million (SME's), this figure includes small firms which employ fewer than 10 people, and makes up over 90 per cent of all firms in the UK, contributing around 40 per cent to the UK's Gross National Product (DTI. 2005). Thus despite being smaller in size it is SME's who tend to create the innovation which drives our economy.

Consideration of what is an SME by Shaw (2005) suggests there is no single definition of a small firm, mainly because of the wide diversity of businesses, however notes for statistical purposes, the Department of Trade and Industry (DTI) in the UK use of the following definition based on firm size: Micro ( $0-9$ employees); Small ( 0 - 49 employees - includes micro); Medium (50 - 249 employees); and Large firms (over 250 employees). In early 2005, however a new definition of a SME took effect, taking into consideration not just firm size, but also turnover. This definition is based on the European Commission's Small and medium enterprises (also SMEs, small and medium businesses, SMBs, and variations thereof) are companies whose headcount or turnover falls below certain limits.

However, the definition of micro, small and medium-sized enterprises is updated to take account of economic developments. The definition of enterprises according to staff headcount and turnover or balancesheet total is essential for identifying businesses able to benefit from European Union (EU) programmes or policies specifically designed for small and medium-sized enterprises (SMEs).

According to Nigeria definition, small and medium enterprise is defined as any enterprise with a maximum asset base of N500 million (excluding land and working capital), and with no lower or upper limit of staff.

\subsection{The Concept Of Quality Management (QM).}

The term Quality management has a specific meaning within many business sectors. This specific definition, which does not aim to assure 'good quality' by the more general definition (but rather to ensure that an organisation or product is consistent), can be considered to have four main components: quality planning, 
quality control, quality assurance and quality improvement. Quality management is focused not only on product/service quality, but also the means to achieve it. Quality management therefore uses quality assurance and control of processes as well as products to achieve more consistent quality. (Beliwoje, 2010)

Quality awareness (or its synonym quality consciousness) is most essential topic for realizing quality and quality integration in practical cases. The concept may be defined very simply: having knowledge of quality.

However, what is the meaning of this, is not at all any simple thing. Awareness is a profound totality of physical, psychological, and philosophical aspects of sensations, perceptions, ideas, attitudes, and feelings related to an individual or a group having knowledge of the abstract and comprehensive object of quality of a certain item, at any given time, or within a given time span. In time dimension, developing of the knowledge and learning become interesting aspects. It may be recognized different depth-levels of intellectual behaviour in learning that may be categorized e.g. according to Bloom's Taxonomy.

Metacognitive readiness and ability to learn learning and to open to question one's own way to think and act are the most sublime achievements in the development of learning. All these phenomena are very essential but also very complex things when developing quality integration in any kind of organization in modern business environments. Explicit knowledge is only a very minor part because most of the knowledge is implicit (or tacit) in this context. There are always also complex connections between consciousness and unconsciousness (sub consciousness). Situation is still more complicated when one is considering possibilities of the collective consciousness and collective unconsciousness.

The International Organization for Standardization (ISO) defines quality as the totality of features and characteristics of a product or service that bear on its ability to satisfy stated or implied needs.

Quality Management (QM) is a method for ensuring that all the activities necessary to design, develop and implement a product or service are effective and efficient with respect to the system and its performance (Deming, 1986). Quality Management is not specific to managing people, but rather is related to improving the quality of goods that are produced in order to satisfy customer demands. QM permeates the entire organisation as it is been implemented. Quality can therefore be identified as a management function because it needs to be planned, implemented, monitored and improved.

Quality gurus like Duran (1950's); Deming (1950's) and Crosby (1980's) have put forth several approaches to improve company performance. Quality Management presents a strategic option and an integrated management philosophy for organisations, which allows them to reach their objectives effectively and efficiently, and to attain competitive advantage (Goldberg and Cole, 2002). Even QM's promoters confess that organisations have not found it easy to implement the Quality Management initiatives and to achieve the desired benefits (Kirk, 2000). More critically, Brown (2000) concluded that there are still organisations where, despite criticism, the quality management philosophy continues to be a central focus of the business and a mechanism for contributing to better performances.

\subsection{Quality Management Awareness In SMES And Large Enterprises}

"Awareness" in any general dictionary, you will find the only listing is as "self-awareness" (meaning "an awareness of one's own personality or individuality"). However, if you look up the word "aware", a much wider meaning is listed, namely "having or showing realization, perception, or knowledge". There not usually existing a general listing of "awareness" as a unique listing, we define it to mean "unique perception and/or knowledge of self and all".

The first part of awareness is as unique perception of knowledge. Examples of knowledge are science, history, society, economics, mathematics, languages and religion. Therefore in one sense to say a person "has greater awareness", it can mean they have greater knowledge of such subjects.

2.4.1. Awareness as unique perception of self or all: In contrast, unique perception of self or all does not require great knowledge of science, only of what a person is "feeling". Unique perception is completely subjective. There are some words that are especially related to this aspect of awareness as they are most commonly used to mean the same thing. These are: Mind, Consciousness, Ethereal, Ether, Being and Self.

2.4.2. Greater perceptual awareness: Unique perception of all is considered a "higher" form of awareness and is a basic concept associated with ideas such as meditation, astral travel, telepathy, spiritual channelling and healing.

2.4.3. Self-aware life: The rational reason that awareness is not usually listed as an independent object in the dictionary is not because the concept does not exist, but because the concept does not exist in reality. The only evidence of awareness is self-aware life forms such as the human being and other higher-order species on planet Earth. There is simply no evidence awareness existing independent of a living thing. 
2.4.4. The idea of Awareness as an independent quality "in theory": Even though awareness as an independently existing quality is considered impossible, it still exists as a theoretical idea. Awareness as an independent quality is an idea.

\section{Methodology}

The data used in this paper was basically primary data of questionnaire analysis that were distributed to the Small business owners in Lagos State Nigeria. However, the study population comprises 100 small business owners located in strategic area of Lagos State, Nigeria and it is made up of male and female. More so, the population also has different material status from single to married. However, spearman's rank correlation coefficient will be adopted as the estimation techniques. However, the formula for Spearman's rank-order correlation is as follows:

$$
\begin{aligned}
& \mathrm{R}=1-\frac{6 \sum \mathrm{d}^{2}}{\mathrm{n}\left(\mathrm{n}^{2}-1\right)} \\
& \text { Where } \quad \begin{aligned}
\mathrm{d} & =\text { the difference between the ranks of each pair. } \\
\mathrm{n} & =\text { number of paired observations }
\end{aligned}
\end{aligned}
$$

\subsection{Discussion of Questionnaire}

The result revealed that 84 respondents Strongly agreed that in their organization they personally conduct regular reviews of quality performance on their product/service and this gives $84 \%$ of the whole respondents but only 16 respondents agreed with the question and this represent $16 \%$ of the total respondents, therefore, we can the conclude that the organization personally conduct regular reviews of quality performance on their product/service.

However, 96 respondents strongly agreed that there is total commitment of all the staffs in all operations and this represent $96 \%$ of the whole respondents and 4 respondents agreed with the question and it constitutes $4 \%$ of the whole respondents. From the analysis we can infer that there is total commitment of all the staffs in all operations in the organization.

90 respondents strongly agreed that their organization give quality issues top priority as criteria when making decisions and this give $90 \%$ of the whole respondents, 4 respondents agreed with the notion and this represents $4 \%$ of the whole respondents while 6 respondents are undecided on the question and they constitutes $6 \%$ of the whole respondents. Therefore we can then conclude that the organisation give quality issues top priority as criteria when making decisions. More so, 70 respondents strongly agreed and 16 respondents agreed with the question been asked and this gives $70 \%$ and $16 \%$ of the whole respondents, 8 and 6 respondents strongly disagreed and disagreed with the question and they constitutes $8 \%$ and $6 \%$ of the whole respondents. Therefore we can deduce from the analysis that in adequate resources and time are allocated for quality management efforts.

Moreover, 88 out of 100 respondents strongly agreed with the question that in their organization emphasis on continuous improvement has been applied in all operations and at all levels and this gives $88 \%$ of the whole respondents and 12 respondents agreed with the notion and this gives $12 \%$ of the total respondents. However, we can then conclude that in the organization emphasis on continuous improvement has been applied in all operations and at all levels. 62 respondents strongly agreed with the question and this gives $62 \%$ of the total respondents, 22 respondents agreed with the notion and its gives $22 \%$ of the whole respondents, while only 16 respondents are undecided about the question and this represents $16 \%$ of the whole respondents, therefore we can then conclude that the organization builds its competiveness on the basis of providing quality products/services.

From the questionnaire, 82 and 10 respondents strongly agreed and agreed with the notion and this gives $82 \%$ and $10 \%$ of the whole respondents but only 8 respondents are undecided about the notion and this represents $8 \%$ of the total respondents, however, from the analysis above we can infer that their Organization has improved at least one feature of its product/service in the past year.

Furthermore, can also infer that since all the 100 respondents strongly agreed with the question and this give $100 \%$ of the total respondents, therefore we can say that quality related training and development is given to all employees in their organization while 44 respondents strongly agreed with the question been asked and this gives $44 \%$ of the total respondents while 52 respondents strongly disagreed with the notion and this represents $52 \%$ of the whole respondents but only 4 respondents are undecided on the notion and its constitutes $4 \%$ of the total respondents. Therefore we can conclude that employees do not accept responsibility for quality in the production process in the organization and from finding while in field of administering the questionnaire, we got to know that is not in all cases that they accept responsibility for quality of product because the management sometimes fail to get the necessary raw materials that will bring better quality of the product.

84 respondents strongly agreed on the question been asked and this gives $84 \%$ of the whole respondents while only 16 respondents are undecided on the notion and this represents $16 \%$ of the total 
respondents, therefore we can then conclude that there is an advanced technological information system on the internet that provide and support implementing advanced quality management system to the customers about product/services while 66 and 18 respondents strongly agreed and agreed with the question been asked and this gives $66 \%$ and $18 \%$ of the whole respondents while 16 respondents strongly disagreed with the notion and this represents $16 \%$ of the total respondents. Therefore, it can be concluded that the organization collects data to monitor changes in customer satisfaction and to know whether there is service delivery satisfaction.

More so, 36 and 20 respondents strongly agreed and agreed that in their organization customer requirement are effectively disseminated and understood throughout the workforce and this constitutes $36 \%$ and $20 \%$ of the total respondents while 4 and 40 respondents strongly disagreed and disagreed that in their organization, customers requirements are effectively disseminated and understood throughout the workforce and this represents $4 \%$ and $40 \%$ of the total respondents. Therefore, we can then conclude that in the organization, customers requirements are not effectively disseminated and understood throughout the workforce while 82 and 18 respondents strongly agreed and agreed with the question and this gives $82 \%$ and $18 \%$ of the whole respondents, however, we can then conclude that the organization make use of customer complaints and feedback to initiate improvements in its product/service.

From the questionnaire analysis, it was also revealed that all the 100 respondents strongly agreed with the question been asked and this gives $100 \%$ of the whole respondents, therefore we can the conclude that the creation of quality awareness among employees is well known in the organization but 58 and 42 respondents strongly agreed and agreed with the question and this represents $58 \%$ and $42 \%$ of the whole respondents, therefore we can infer from the analysis that the organization supports any changes in culture or structure required to adapt to changes in the business environment.

100 respondents strongly agreed with the notion and this gives $100 \%$ of the total respondents and we can deduced that the organization conducts periodic examinations of the materials supplied to ensure conformity with the standard specification while 56 out of 100 respondents strongly agreed that the organization develops relationship with their supplier that leads to continuous improvements in quality and this gives $56 \%$ of the total respondents while 44 out of 100 respondents agreed that the organization develops relationship with their supplier that leads to continuous improvements in quality and this represents $44 \%$ of the total respondents. Moreover, from the analysis above, we can conclude that the organization develops relationship with their supplier that leads to continuous improvements in quality.

16 out 100 respondents strongly agreed that the level of awareness on quality management in Nigeria is very high and this gives $16 \%$ of the whole respondents, 10 out of 100 respondents agreed that the level of awareness on quality management in Nigeria is very high and this constitutes $10 \%$ of the whole respondents. Moreover, 46 out of 100 respondents strongly disagreed that the level of awareness on quality management in Nigeria is very high and this represents $46 \%$ of the whole respondents while 28 out of 50 respondents disagreed that the level of awareness on quality management in Nigeria is very high and this gives $28 \%$ of the whole respondents. Therefore we can then conclude that the level of awareness on quality management in Nigeria is not very high.

Finally we can conclude from the questionnaire's result that the opinions, feelings, and the pulse of some key SME practitioners in exploring the extent to which quality management practice is applied has an impact on the organisations and this gives $100 \%$ of the whole respondents while 88 out of 100 respondents strongly agreed that the level of awareness of the Nigerian media and government has raise awareness on quality management in Nigeria and this represents $88 \%$ of the total respondents and 6 out of 100 respondents agreed that the level of awareness of the Nigerian media and government has raise awareness on quality management in Nigeria but only 6 out of 100 respondents disagreed that the level of awareness of the Nigerian media and government has raise awareness on quality management in Nigeria while nobody are undecided on the notion. Therefore, we can then infer that the level of awareness of the Nigerian media and government has raise awareness on quality management in Nigeria.

\subsection{Discussion Of Findings}

\subsubsection{Research Hypothesis 1}

NULL HYPOTHESIS (Ho): Total quality management practices have no significant effect on Small and Medium Enterprises in Nigeria.

ALTERNATIVE HYPOTHESIS (H1): Total quality management practices have a significant effect on Small and Medium Enterprises in Nigeria.

From the result, the Spearman's rank correlation coefficient ${ }^{\circledR}$ is given as $0.811^{* *}$, and this give a strong and positively significant relationship is established as reflected in the Spearman's correlation coefficient calculated $\mathrm{R}$ value which is 0.811 , and the tabulated value using $5 \%$ level of significant which is 0.05 .

However, since the Spearman's rank correlation coefficient calculated from the result with the use of special package for social sciences is greater than tabulated value, the decision rule is to accept the alternative 
hypothesis and reject the null hypothesis, then concludes that Total quality management practices have a significant effect on Small and Medium Enterprises in Nigeria.

\subsubsection{Research Hypothesis 2}

NULL HYPOTHESIS (Ho): Challenges encountered by the SME has not lead to successful total quality management programmes within the organisation.

ALTERNATIVE HYPOTHESIS (H1): Challenges encountered by the SME has lead to successful total quality management programmes within the organisation.

The result of the Spearman's correlation coefficient $r=.779^{* *}$, and this give a strong and positively significant relationship is established as reflected in the Spearman's correlation coefficient calculated $\mathrm{R}=0.779$, and tabulated value using $5 \%$ level of significant which is 0.05 .

Therefore since the Spearman's rank correlation coefficient calculated value is greater than tabulated value, we can then make use of the decision rule to accept the alternative hypothesis and reject the null hypothesis, then concludes that the correlation is positive and strong correlation and that Challenges encountered by the SME has lead to successful total quality management programmes within the organisation.

\section{Recommendations}

Therefore from the analysis, we can make the following recommendation based on our findings;

1. The management team must try to understand that the management of quality requires both focus on longerterm strategic leadership, as well as day-to-day operational management.

2. Those business owners in Lagos State, researchers and practitioners should focus on the critical factors identified herein and employ this survey instrument to manage and better understand the nature of level of awareness of quality management practices in SMEs in Nigeria and over longer time periods.

3. Furthermore, more research work should be extended in scope of existing quality management literature to the SMEs in Nigeria using small business owners throughout an entire state and contributes to theory about the nature of quality.

4. More experience quality management practitioners should be involved in the decision making of the organization.

5. There should be more training and development coupled with workshop should be in place for the employees to make them more effective and efficient in their work.

6. A better welfare package should be given to the employees in other for the employees to be more productive in nature.

7. Nigerian Government still needs to empower the SMEs in the country by diverting some fund to the industry so that they will be more efficient.

8. Quality management practice should be encouraged in all the organizations, so that it will be well known to a lot of people.

9. Good quality management programmes should be in place in the organization to enable all the staffs to learn and undergo the process of quality management in their organization.

10. The critical success factors should be adhering to strictly to achieve better quality management practice of SMEs in Nigeria.

\section{Conclusion}

Quality management has a specific meaning within many business sectors. This specific definition, which does not aim to assure 'good quality' by the more general definition (but rather to ensure that an organisation or product is consistent), can be considered to have four main components: quality planning, quality control, quality assurance and quality improvement. Quality management is focused not only on product/service quality, but also the means to achieve it. Quality management therefore uses quality assurance and control of processes as well as products to achieve more consistent quality.(Lawal, 2008).

One of the important decisions for a firm on the journey to quality concerns the extent to which quality management should be implemented. There are many research on the impact of quality management on business performance that this paper has discussed extensively in the literature review and some of the literature has vividly take a look at the benefits of quality management such as improvements to the bottom-line, market share, and productivity, the improvement of product and service quality is also widely discussed in the literature as an appropriate strategy for firms to pursue in order to achieve competitive advantage in the marketplace. However, because of the strategic advantages that quality improvement might bring, many firms have embraced the principles of quality management in their operations. The level of quality management implementation seems to reflect the desire of a firm to improve its performance and to prosper is network in achieving organizational goal and objectives. While existing studies tend to investigate the important facets of quality 
management implementation, very little research has been devoted to understanding the level of awareness of quality management practices in SMEs in Nigeria, but this paper has tremendously done justice and adds more value to the existing literature in this area of study.

\section{References}

[1]. Ajayi, A (2004). Analysis of Quality Management on Organizational Performance, Journal vol 33, pg 44-53, University Press Ibadan.

[2]. Beliwoje, S.H. (1991). Management Practice in broader perspectives, textbook $3^{\text {rd }}$ edition, pg 102-134, Macgraw Hill Publication.

[3]. Brown (2000) Management and Organizational Performance, textbook $2^{\text {nd }}$ edition, pg 78-86, Macgraw Hill world Publication limited.

[4]. Crosby, G.Y. (1980). Firms and Quality Management Practice, Journal vol 27, pg 33-49, Macgraw Hill Publication limited.

[5]. Dale H (2003) Impact of Training and Development on Firm Performance, Journal vol 17, pg 41-58, DDT Press.

[6]. Deming F. T. \& Duran, D.D. (1950) Impact of leadership on Quality Management Control, Journal vol 55, pg 87-99, Meltwint Press limited.

[7]. Deming F (1986) Total Quality Management Control, broader perspectives, $3^{\text {rd }}$ edition, pg 32-54, BBM Publication limited.

[8]. European Commission (2005) Small and Medium Scale Enterprises in European Countries, European Publication.

[9]. Goh K. J. \& Ridgeway, R.E. (1984) Customers Relations and Firm Quality in an Organization, Journal vol 9, pg 38-49, Height Press limited.

[10]. Gosen, W.T. \& Westy, D.O. (2005). Small and Medium Scale Enterprises and Developing Countries, Journal vol 7, pg 17-29, Sandy Publication limited.

[11]. Gooldberg, D.A \& Cole, M.S. (2004). Effective Total Quality Management Practice in an Organization, textbook $2^{\text {nd }}$ edition, Publication limited.

[12]. Kirk R (2000) Total Quality Management, a broader perspective, $2^{\text {nd }}$ edition, pg 29-41, Height Press.

[13]. Oluseye, G.M. (2014) Strategic Planning and Policy, a wider perspective, textbook $1^{\text {st }}$ edition, pg 27-41, GBT Press limited

[14]. Onugu D (2005) Prospects and Problems of Large Business Enterprise in Nigeria, textbook $2^{\text {nd }}$ edition, pg 17-35, Macmillan Press limited.

[15]. Usher G (2004) Large Business Enterprises and Organizational Effectiveness, $1^{\text {st }}$ edition, pg 19-27, Macgraw Hill Publication limited. 